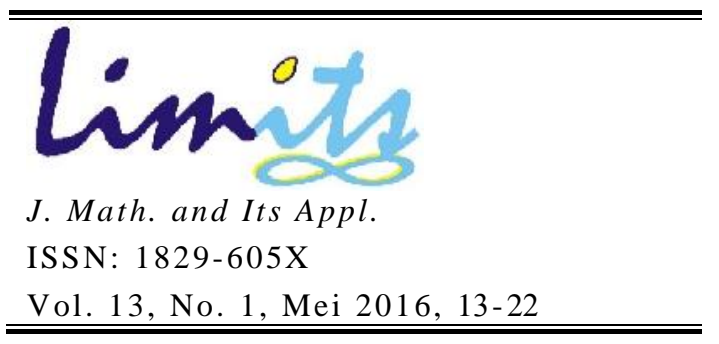

\title{
DESAIN PENGENDALIAN PINTU AIR DENGAN METODE SLIDING MODE CONTROL (SMC)
}

\author{
Moh. Fahmi Muzaki', Erna Apriliani², Sri Suprapti $\mathbf{H}^{3}$ \\ 1,2,3 Jurusan Matematika, FMIPA ITS \\ april@matematika.its.ac.id
}

\begin{abstract}
Abstrak
Banjir sungai Bengawan Solo disebabkan oleh curah hujan yang sangat tinggi di area hulu. Salah satu cara untuk mengatasinya adalah pembuatan sodetan di desa Pelangwot, Laren, Lamongan. Sodetan tersebut mempunyai pintu air yang pengoperasiannya dilakukan secara manual. Hal ini rawan terjadinya kesalahan yang dapat menyebabkan banjir. Oleh karena itu, dibutuhkan suatu control yang mengendalikan pintu air tersebut secara otomatis dan salah satunya adalah metode Sliding Mode Control (SMC). Hasil simulasi dengan metode SMC memperlihatkan bahwa saat ketinggian air sungai belum mencapai Hd (ketinggian air sebelum pintu air yang diinginkan), maka ketinggian air selanjutnya akan menuju ke nilai $\boldsymbol{Z}_{\boldsymbol{d}}$ (ketinggian air setelah pintu air )dan pintu air bergerak sedemikian hingga ketinggian air menuju ke nilai $\boldsymbol{H}_{\boldsymbol{d}}$. Sedangkan saat ketinggian air sungai sudah mencapai $\boldsymbol{Z}_{\boldsymbol{d}}$, maka ketinggian air selanjutnya akan berada di sekitar nilai Hd dan pintu air akan bergerak sedemikian hingga ketinggian air stabil di nilai $\boldsymbol{H}_{\boldsymbol{d}}$. Metode SMC tidak mampu mengendalikan ketinggian air sungai saat debit air sungai sangat besar.
\end{abstract}

Kata kunci: Pintu air, Sliding Mode Control (SMC), sodetan Pelangwot

\section{Pendahuluan}

Sungai Bengawan Solo merupakan salah satu sungai terpanjang di Indonesia yang melewati dua provinsi, yaitu Jawa Tengah dan Jawa Timur. Sungai ini mempunyai dua area hulu yang terletak di kabupaten Wonogiri dan Ponorogo yang bertemu di kabupaten Ngawi, kemudian bermuara ke daerah hilir di kabupaten Gresik. Sungai ini memiliki curah hujan yang tinggi di daerah hulu dan banyak mengalami perubahan fungsi lahan, sehingga sungai ini mengalami banjir di bagian hilir khususnya di wilayah Bojonegoro, Tuban, Lamongan dan Gresik. Selain disebabkan oleh debit yang meningkat dari area hilir, banjir Sungai Bengawan Solo juga disebabkan oleh sedimentasi yang terjadi [1]. Untuk mengatasi banjir, sungai ini mengalami banyak modifikasi 
pada daerah alirannya, yaitu pembuatan waduk, bendungan, dan sodetan (floodway).

Salah satu modifikasi dari sungai Bengawan Solo adalah pembuatan sodetan Pelangwot yang berlokasi di desa Pelangwot kecamatan Laren kabupaten Lamongan dengan panjang sekitar $13 \mathrm{~km}$ dan lebar sekitar $100 \mathrm{~m}$ yang berfungsi untuk menyalurkan debit air dari sungai Bengawan Solo untuk dibuang langsung ke laut Jawa[2]. Dengan adanya modifikasi tersebut, aliran sungai Bengawan Solo mempunyai muara di dua tempat yaitu di daerah Lamongan dan Gresik.

Sodetan Pelangwot memiliki pintu air yang dioperasikan secara manual dengan melihat langsung ketinggian air sungai. Kondisi ini rawan terjadinya kesalahan manusia dalam pengoperasiannya yang dapat mengakibatkan banjir di sekitar dua muara sungai. Sehingga dibutuhkan suatu pengendali agar pintu air di sodetan tersebut dapat membuka dan menutup secara otomatis. Hal ini akan membantu pencegahan banjir di salah satu maupun kedua daerah muara sungai.

Pengendalian pintu air secara otomatis dapat menggunakan Metode Ensemble Kalman Filter (EnKf) Berbasis Nonlinear Model Predictive Control (NMPC)[3]. Metode EnKf digunakan untuk memprediksi ketinggian air dan debit air saat mencapai bendungan yang selanjutnya akan digunakan sebagai inputan untuk mengendalikan pintu air. Sedangkan metode NMPC digunakan untuk memperoleh besaran optimum buka pintu air. Hasilnya adalah metode tersebut efektif untuk mengestimasi debit dan ketinggian aliran sungai dengan RMSE (Root Mean Square Error) kurang dari 1 dan perubahan opening gate kurang dari $25 \%$.

Pada paper ini digunakan alternatif lain yaitu penerapan metode Sliding Mode Control (SMC) untuk mengendalikan pintu air di sodetan Pelangwot secara otomatis. Metode SMC sangat baik saat digunakan pada sistem non linear. Tetapi SMC memiliki kekurangan yaitu munculnya chattering yang dapat menyebabkan ketidak-stabilan sistem. Untuk mencegahnya, maka diberlakukan suatu boundary layer pada metode tersebut. Metode SMC memiliki dua jenis pengendali yaitu Static Sliding Mode Control dan Dynamic Sliding Mode Control[4]. Pada dasarnya dua jenis pengendali tersebut mempunyai kesamaan dalam memperoleh sistem pengendalinya. Hanya saja pada Dynamic Sliding Mode Control, order dari suatu model matematika dinaikkan satu tingkat lebih tinggi dari order sebelumnya. Sehingga Dynamic Sliding Mode Controlmempunyai kesulitan yang lebih tinggi daripada Static Sliding Mode Control dalam pembentukan suatu sistem pengendali. Tetapi Dynamic Sliding Mode Control mempunyai performansi yang lebih baik daripada Static Sliding Mode Control[4].

\section{Pemodelan Matematika Sistem Pintu Air}

Sodetan pelangwot merupakan bendungan gerak yang memiliki dua bagian utama, yaitu reservoir yang digunakan untuk menampung air dan pintu air yang digunakan untuk mengalirkan air secara bertahap sesuai yang kebutuhan. Pada reservoir dapat diperoleh suatu model matematika yang 
didapatkan dari persamaan kontinuitas dengan mengasumsikan bahwa aliran air tidak elastis yang dapat dinyatakan dalam Persamaan (1) [5].

$$
\frac{a}{d}=\frac{1}{A[H(\tau)]}\left(Q_{i \imath}-Q_{G}\right)
$$

Sedangkan model matematika dari pintu air merupakan persamaan nonlinear yang dinyatakan oleh Persamaan (2) dan (3)[5].

$$
\begin{aligned}
& Q_{G}=\varepsilon \cdot O \cdot A_{G} \cdot \sqrt{2 \cdot g \cdot \Delta} \\
& \Delta H=H-Z_{D}
\end{aligned}
$$

Dengan mensubstitusikan Persamaan (3) ke Persamaan (2) dan dilanjutkan substitusi ke Persamaan (1) akan diperoleh suatu model matematika sistem pintu air sebagai berikut:

$$
\dot{H}(t)=\frac{1}{A[H(t)]}\left(Q_{i 1}(t)-b \cdot O \cdot \sqrt{H(t)-Z_{\nu}}\right.
$$

$$
\begin{array}{cll}
\text { dengan } & b= & =\varepsilon \cdot A_{G} \cdot \sqrt{2 \cdot g} \text { dan } \\
H & : & \text { Ketinggian air sebelum pintu air }(\mathrm{m}) \\
A & : & \text { Luas penampang sungai }\left(\mathrm{m}^{2}\right) \\
Q_{i 1} & : & \text { Debit air yang masuk melewati pintu air }\left(\mathrm{m}^{3} / \mathrm{s}\right) \\
Q_{G} & : & \text { Debit air yang keluar melewati pintu air }\left(\mathrm{m}^{3} / \mathrm{s}\right) \\
O & : & \text { Pembukaan pintu air }(\%) \\
A_{G} & : & \text { Total luas pintu air }\left(\mathrm{m}^{2}\right) \\
g & : & \text { Percepatan gravitasi }\left(\mathrm{m}^{2} / \mathrm{s}\right) \\
\Delta H & : & \text { Selisih ketinggian air sungai sebelum dan setelah pintu air }(\mathrm{m}) \\
Z_{D} & : & \text { Ketinggian air setelah pintu air }(\mathrm{m}) \\
\varepsilon & : & \text { Parameter yang dapat divariasikan dan diestima-sikan sehingga } \\
& & \text { mendekati gerakan pintu air pada kenyataan. }
\end{array}
$$

\section{Desain Kendali Pintu Air}

Model matematika sistem pintu air pada Persamaan (4) merupakan persamaan berorde satu, sehingga order persamaan tersebut dinaikkan menjadi orde dua agar memenuhi syarat Dynamic Sliding Mode Control. Misalkan $\mathrm{H}_{\mathrm{d}}$ merupakan tinggi yang diinginkan, maka tracking error dapat dinyatakan oleh:

$$
\begin{aligned}
& e=H-H_{d} \\
& \dot{e}=\dot{H}-\dot{H}_{d}
\end{aligned}
$$

Nilai $H_{d}$ diasumsikan konstan, maka $\dot{H}_{d}=0$, sehingga diperoleh :

$$
\dot{e}=\dot{H}
$$

Dari tracking error, fungsi switching dapat dinyatakan oleh persamaan:

$$
S=\dot{H}+\lambda\left(H-H_{d}\right)
$$

Sehingga turunan pertama dari $S$ adalah :

$$
\begin{aligned}
& \dot{S}=\ddot{H}+\lambda\left(\dot{H}-\dot{H}_{d}\right) \\
& \dot{S}=\ddot{H}+\lambda \dot{H}
\end{aligned}
$$


Dengan mensubstitusikan Persamaan (4) dan turunan kedua dari $H$ ke Persamaan (9) akan diperoleh :

$$
\dot{S}=\frac{1}{A}\left(\frac{H \dot{Q}_{i 1}-Q_{i \dot{1}} \dot{H}+\lambda Q_{i:}}{H}\right)-\frac{b O}{A}\left(\frac{H \dot{H}}{2 H \sqrt{H-Z_{L}}}-\frac{2 \dot{H}\left(H-Z_{D}\right)+2 \lambda\left(H-Z_{L}\right)}{2 H \sqrt{H-Z_{L}}}\right)
$$

Selanjutnya ditentukan nilai estimasi pengendali $\widehat{O}$ yang diperoleh dari Persamaan (10) dengan nilai $\dot{S}=0$, sehingga diperoleh :

$$
\widetilde{O}=\frac{2 \sqrt{H-Z_{D}}\left(H \dot{Q}_{i 1}-Q_{i 1} \dot{H}+\lambda \quad Q_{i 1}\right)}{b\left(H \dot{H}-2 \dot{H}\left(H-Z_{D}\right)+2 \lambda\left(H-Z_{U}\right)\right)}
$$

Dengan mensubstitusikan Persamaan (11) ke persamaan control law pada SMC akan diperoleh:

Misalkan :

$$
O=\frac{2 \sqrt{H-Z_{D}}\left(H \dot{Q}_{t i}-Q_{l i} \dot{H}+\lambda Q_{\ell_{i}}\right)}{b\left(H \dot{H}-2 \dot{H}\left(H-Z_{L}\right)+2 \lambda\left(H-Z_{L}\right)\right)}-K S
$$

$$
\begin{array}{cl}
x=H \dot{Q}_{i 1}-Q_{i 1} \dot{H}+\lambda & Q_{i 1} \\
y=H \dot{H}-2 \dot{H}\left(H-Z_{D}\right)+2 \lambda & \left(H-Z_{D}\right)
\end{array}
$$

maka persamaan (12) dapat ditulis menjadi :

$$
O=\frac{2 x \sqrt{H-Z_{D}}}{b y}-K s
$$

Dengan mensubstitusikan Persamaan (13) ke Persamaan (10) maka diperoleh:

$$
\dot{S}=\frac{b y K S \quad(S)}{2 A H^{2} \sqrt{H-Z_{D}}}
$$

Selanjutnya akan ditentukan nilai $K$ agar memenuhi kondisi sliding pada SMC dan diperoleh :

$$
K=m\left(-\frac{-2 \eta H^{2} \sqrt{H-Z_{D}}}{b y}\right)
$$

Desain kendali pintu air didapatkan dengan mensubstitusikan Persamaan (15) ke Persamaan (12) dan menerapkan boundary layer untuk meminimalkan chattering yang dinyatakan oleh persamaan sebagai berikut :

$$
O=\frac{2 x \sqrt{H-Z_{\nu}}}{b y}-m\left(-\frac{-2 \eta H^{L} \sqrt{H-Z_{\nu}}}{b y}\right) s i \quad\left(\frac{s}{\Phi}\right)
$$

\section{Simulasi dan Hasil}

Desain kendali pada Persamaan (16) akan disimulasikan dengan tujuan untuk mengetahui pengoperasian pintu air ketika terjadi perubahan ketinggian air sungai. Simulasi tersebut menggunakan masukan data debit air dengan selang waktu per jam. Selain debit air, pada simulasi dibutuhkan beberapa nilai parameter yang telah ditentukan. Sebagian dari nilai-nilai itu diperoleh dari profil sodetan (floodway) Pelangwot. Nilai parameter yang digunakan dalam simulasi pengendalian pintu air dapat dilihat pada Tabel 1. 
TABEL 1. Nilai parameter yang dibutuhkan pada simulasi

\begin{tabular}{lccc}
\hline \multicolumn{1}{c}{ Keterangan } & Simbol & Nilai & Satuan \\
\hline \hline Gravitasi bumi & $g$ & 9,8 & m/detik ${ }^{2}$ \\
Parameter yang divariasikan & $\varepsilon$ & 10 & \\
Konstanta positif $\lambda$ & $\lambda$ & 1 & \\
Konstanta positif $\eta$ & $\eta$ & 0,1 & \\
Selang waktu & $t$ & 1 & Jam \\
Boundary layer & $\Phi$ & $1 \times 10^{-8}$ & \\
Ketinggian air maksimal & $H_{m}$ & 10 & $\mathrm{M}$ \\
Ketinggian setelah pintu air & $Z_{D}$ & 3 & $\mathrm{M}$ \\
Lebar sungai & $l$ & 37,5 & $\mathrm{M}$ \\
Total luas pintu air & $A_{\mathrm{G}}$ & 185,625 & $\mathrm{~m} / \mathrm{detik}^{2}$ \\
\hline
\end{tabular}

Debit air saat musim kemarau yang bernilai kurang dari $10 \mathrm{~m}^{3} /$ detik dijadikan sebagai inputan dengan ketinggian air awal bernilai 3,26 $\mathrm{m}$ dan pintu air tertutup total. Sehingga diperoleh nilai awal $\mathrm{H}(1)=3,26 \mathrm{~m}$ dan $\mathrm{OP}(1)$ $=0 \%$ yang akan digunakan dalam simulasi pengoperasian pintu air pada musim kemarau. Grafik ketinggian air sungai sebelum pintu air pada musim kemarau dapat terlihat pada Gambar 1.

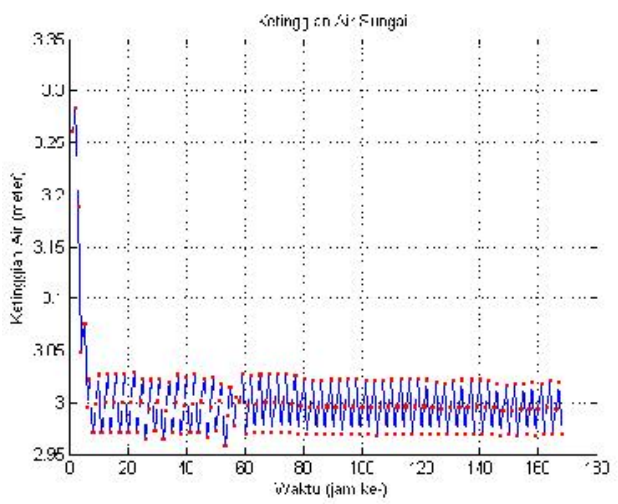

Gambar 1.Ketinggian air sungai pada musim Kemarau

Berdasarkan Gambar 1, ketinggian air sungai sebelum pintu air berada pada kisaran 3 m yang merupakan nilai $Z_{D}$ di simulasi ini. Hal ini dikarenakan debit air sungai bernilai sangat kecil, yaitu kurang dari $10 \mathrm{~m}^{3} /$ detik di tiap jam. Sedangkan grafik pengoperasian pintu air pada musim kemarau tampak pada Gambar 2. 


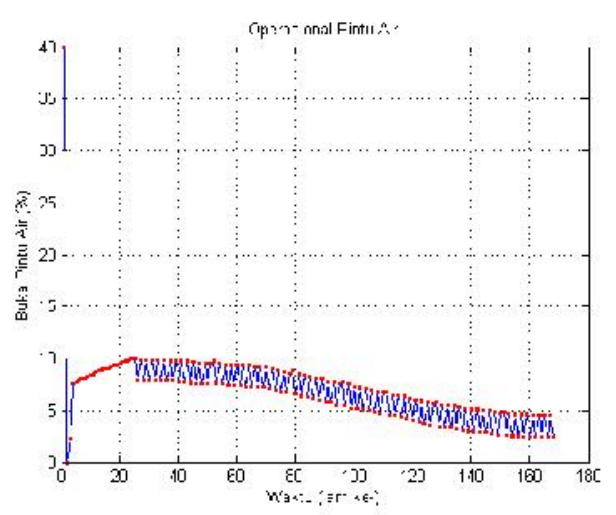

Gambar 2. Pengoperasian pintu air pada musim kemarau

Pada Gambar 2 terlihat bahwa pintu air terbuka dengan persentase maksimal kurang dari 3\% dan sebagian besar tertutup pada waktu tertentu. Hal ini dikarenakan bahwa debit air yang masuk ke pintu air relatif kecil sehingga membuat pintu air terbuka sangat kecil. Selain itu, Gambar 2 juga memperlihatkan bahwa pengoperasian pintu air mengikuti perubahan ketinggian air sebelum pintu air. Ketika ketinggian air sebelum pintu air turun maka pengoperasian pintu air juga akan turun dan sebaliknya. Tetapi saat ketinggian air sebelum pintu air kurang dari $Z_{D}$, pintu air tertutup maksimal.

Selanjutnya debit air saat musim Hujan yang memiliki nilai pada interval $600 \mathrm{~m}^{3} /$ detik $-1.500 \mathrm{~m}^{3} /$ detik dijadikan sebagai inputan. Debit air tersebut memiliki ketinggian air awal bernilai 5,62 $\mathrm{m}$ atau $\mathrm{H}(1)=5,62 \mathrm{~m}$. Sementara itu, pintu air terbuka setinggi 2,80 m dari total tinggi pintu air sebesar $7 \mathrm{~m}$ atau $\mathrm{OP}(1)=40 \%$. Grafik ketinggian air sungai sebelum pintu air pada musim hujan dapat terlihat pada Gambar 3.

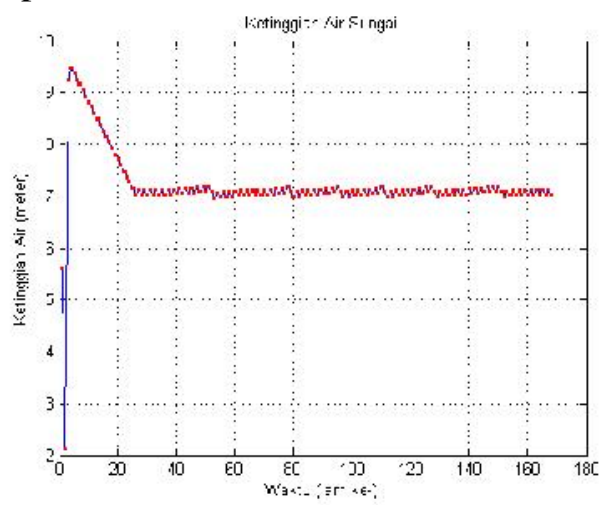

Gambar 3. Ketinggian air sungai pada musim hujan

Pada Gambar 3 tampak bahwa ketinggian air sungai sebelum pintu air dikontrol oleh pengendali SMC pada kisaran $7 \mathrm{~m}$ yang merupakan nilai ketinggian air yang diinginkan. Gambar 3 memperlihatkan bahwa ketinggian air sungai sebelum pintu air masih dalam rentang yang aman jika dibandingkan dengan ketinggian maksimal sebesar $10 \mathrm{~m}$ pada musim hujan. 
Sedangkan grafik pengoperasian pintu air pada musim hujan terlihat pada Gambar 4.

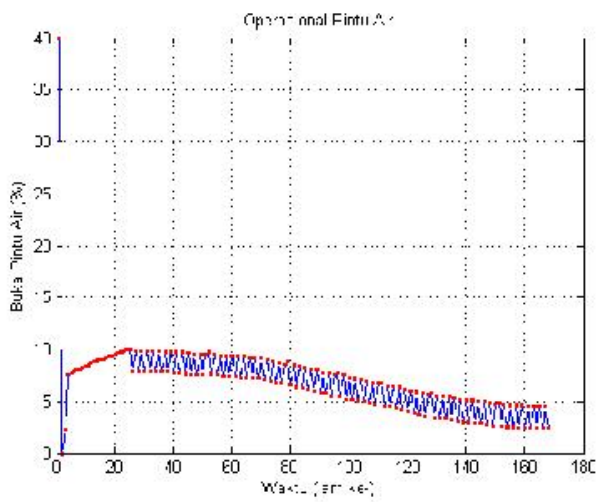

Gambar 4. Pengoperasian pintu air pada musim Hujan

Pada Gambar 4 terlihat bahwa pintu air terbuka pada kisaran 0-10\%. Hanya pada nilai awal yang jauh lebih tinggi dan pada jam ke-2 sampai ke-3 yang kurang dari 5\%. Dari Gambar 4 tampak bahwa pengoperasian pintu air mengikuti perubahan ketinggian air sebelum pintu air. Ketika ketinggian air sebelum pintu air turun maka pengoperasian pintu air juga akan turun dan sebaliknya. Hal ini untuk mempertahankan ketinggian air sungai sebelum pintu air pada ketinggian $7 \mathrm{~m}$ yang merupakan nilai $H_{d}$.

Selain adanya perubahan debit air, simulasi pengendalian pintu air ini dilakukan dengan mengubah nilai parameter yang telah dikonstankan. Hal ini bertujuan untuk mengetahui karakteristik metode SMC ketika terjadi perubahan dari dalam sistem dengan memperbesar atau memperkecil nilai parameter.

Pada simulasi sebelumnya, $Z_{D}$ (ketinggian air setelah pintu air) ditentukan bernilai $3 \mathrm{~m}$. Sedangkan pada bagian ini, nilai tersebut akan diubah-ubah dan dianalisa hasilnya. Grafik ketinggian air sebelum pintu air saat terjadinya perubahan $Z_{D}$ dapat dilihat pada Gambar 5 .

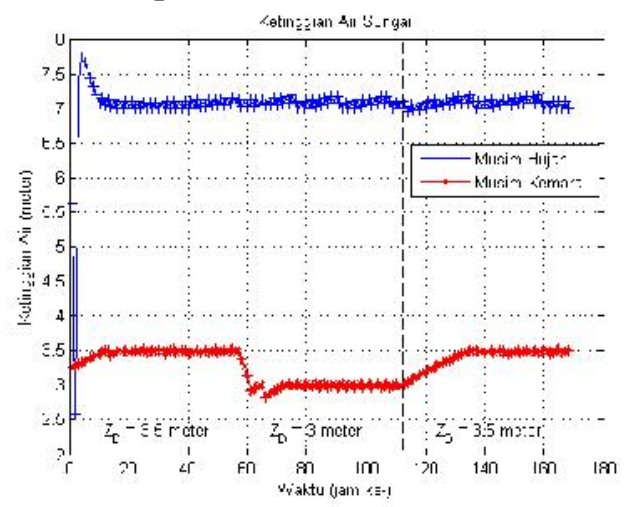

Gambar 5. Ketinggian air sungai saat terjadi perubahan $Z_{D}$ (ketinggian air setelah pintu air). 
Gambar 5 memperlihatkan bahwa pada saat musim hujan, ketinggian air berada di kisaran $7 \mathrm{~m}$ yang merupakan nilai $H_{d}$ saat terjadi perubahan $Z_{D}$. Hal ini dikarenakan ketinggian air sungai sudah melewati nilai $H_{d}$ sehingga ketinggian air pada waktu berikutnya akan stabil di nilai $H_{d}$. Sementara itu, pada saat musim kemarau terlihat bahwa ketinggian air berada di sekitar nilai $Z_{D}$ saat terjadi perubahan nilai tersebut. Hal ini disebabkan ketinggian air pada saat musim kemarau tidak pernah melewati nilai $H_{d}$ sehingga ketinggian air pada waktu berikutnya akan stabil di nilai $Z_{D}$. Grafik pengopera-sian pintu air saat terjadi perubahan nilai $Z_{D}$ dapat dilihat pada Gambar 6.

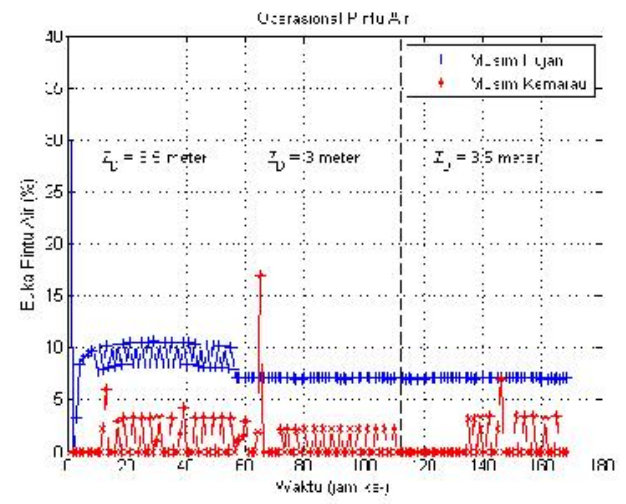

Gambar 6. Pengoperasian pintu air saat terjadi perubahan $Z_{D}$ (ketinggian air setelah pintu air).

Pada Gambar 6 tampak bahwa pengoperasian pintu air mengarahkan ketinggian air sebelum pintu air ke nilai $H_{d}$ atau $Z_{D}$ sesuai penjelasan sebelumnya tentang kapan ketinggian air sebelum pintu air menuju nilai $H_{d}$ atau $Z_{D}$.

Selain nilai $Z_{D}$ yang dikonstankan bernilai $3 \mathrm{~m}$, nilai $H_{d}$ (ketinggian air sebelum pintu air yang diinginkan) juga dikonstankan bernilai $7 \mathrm{~m}$. Pada bagian ini, nilai tersebut akan diubah-ubah untuk melihat karakteristik metode SMC ketika terjadi perubahan $H_{d}$. Grafik ketinggian air sebelum pintu air saat terjadinya perubahan $H_{d}$ dapat dilihat pada Gambar 7.

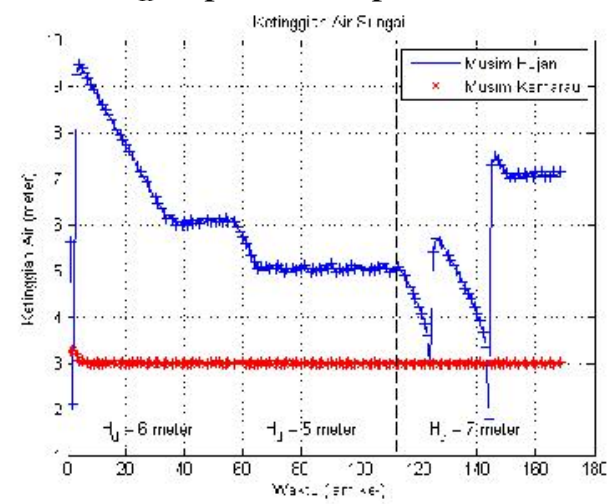

Gambar 7. Ketinggian air sungai saat terjadi perubahan $H_{d}$ (ketinggian air sebelum pintu air yang diinginkan). 
Pada Gambar 7 tampak bahwa pada saat musim hujan ketika $H_{d}$ bernilai 6 dan $5 \mathrm{~m}$, ketinggian air berada pada kisaran nilai $H_{d}$. Sedangkan ketika $H_{d}$ bernilai $7 \mathrm{~m}$, grafik ketinggian air sebelum pintu air menuju nilai $Z_{\nu}$. Hal ini berarti ketika terjadinya perubahan $H_{d}$ dan ketinggian air sebelum pintu air mencapai nilai $H_{d}$, maka ketinggian air pada waktu berikutnya akan berada di kisaran $H_{d}$. Sedangkan ketika ketinggian air sebelum pintu air tidak mencapai nilai $H_{d}$, maka ketinggian air pada waktu berikutnya menuju ke arah $Z_{D}$. Grafik pengoperasian pintu air saat terjadinya perubahan $H_{d}$ dapat dilihat pada Gambar 8.

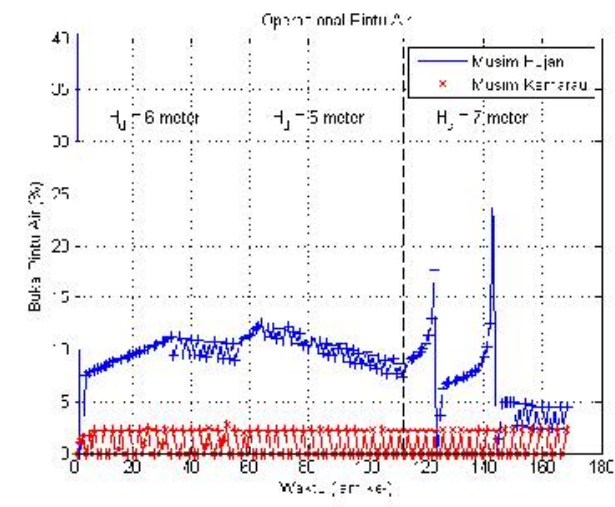

Gambar 8. Pengoperasian pintu air saat terjadi perubahan $H_{d}$ (ketinggian air sebelum pintu air yang diinginkan).

Gambar 8 tampak bahwa pengoperasian pintu air juga mengarahkan ketinggian air sebelum pintu air ke nilai $H_{d}$ atau $Z_{D}$ sesuai ketinggian air yang diinginkan.

\section{Kesimpulan}

Berdasarkan analisis dan pembahasan yang telah disajikan pada bab sebelumnya, dapat disimpulkan beberapa hal sebagai berikut:

1) Penerapan metode Sliding Mode Control (SMC) pada pengendalian pintu air memperlihatkan bahwa:

a. Saat debit air normal akan menyebabkan ketinggian air sungai berubah secara normal juga. Metode SMC mampu mengendalikan pintu air mengikuti perubahan ketinggian air sungai. Ketika ketinggian air sungai tinggi maka pembukaan pintu air akan besar dan sebaliknya.

b. Saat debit air sangat besar dengan rata-rata $21.000 \mathrm{~m}^{3} /$ detik dapat menyebabkan ketinggian air sungai menjadi sangat tinggi. Hal ini menyebabkan terjadinya banjir dan metode SMC tidak mampu mengatasi banjir tersebut. Meskipun pintu air terbuka 100\% (terbuka total).

c. Ketika terjadi perubahan nilai parameter di dalam sistem, maka didapatkan beberapa hasil sebagai berikut:

- Saat ketinggian air sungai belum melewati nilai $H_{d}$, maka ketinggian air pada waktu berikutnya akan menuju ke nilai 
$Z_{D}$ dan pintu air bergerak sedemikian hingga ketinggian air stabil $Z_{D}$

- Saat ketinggian air sungai sudah melewati nilai $H_{d}$, maka ketinggian air pada waktu berikutnya akan stabil di nilai $H_{d}$ dan pintu air bergerak sedemikian hingga ketinggian air stabil $H_{d}$

\section{Daftar Pustaka}

[1] Mudjib, C.M. dan Lasminto,U. (2013), "Studi Angkutan Sedimen Sudetan Pelangwot-Sedayu Lawas Sungai Bengawan Solo," Jurnal Teknik POMITS, vol. 2, pp. 253-258.

[2] Lusiana, D.(2011), "Studi Peningkatan Kapasitas Saluran Pelangwot Untuk Pengendalian Banjir Sungai Bengawan Solo," Tugas Akhir Jurusan Teknik Sipil, FTSP ITS, Surabaya

[3] Purnaningrum, E. (2014), "Pengendalian Pintu air Bendung Gerak Dengan Metode Ensemble Kalman Filter Berbasis Nonlinear Model Predictive Control (NMPC)," Thesis Jurusan Matematika, FMIPA ITS, Surabaya

[4] Herlambang, T. (2010), "Desain Pengendalian Ketinggian Air dan Temperatur Uap pada Sistem Steam Drum Boiler dengan Metode Sliding Mode Control (SMC)," Tugas Akhir Jurusan Matematika, FMIPA ITS, Surabaya

[5] Zhou, W., Thoresen, H. and Glemmstad, B. (2012), "Application of Kalman filter based nonlinear MPC for flood gate control of hydropower plant," Power and Energy Society General Meeting, 2012 IEEE, pp. 1-4. 